\title{
RESPONSABILIDAD, PERDÓN Y JUSTICIA COMO MANIFESTACIONES DE LA CONCIENCIA JURÍDICA UNIVERSAL ${ }^{1}$
}

\author{
Antônio Augusto Cançado Trindade ${ }^{2}$
}

\section{INTRODUCCIÓN}

Constituye para mí motivo de gran honor poder comparecer a esta ceremonia de incorporación, como Profesor Visitante Honoris Causa, de la Universidad Mayor de Nuestra Señora del Rosario, por decisión de su ilustre Claustro. Ésto me proporciona (...) la ocasión de compartir algunas reflexiones con los Profesores y estudiantes de la Universidad del Rosario, así como los integrantes del Diplomado en los Sistemas Internacional y de Derecho Interno de Protección de Derechos Humanos copatrocinado por el Ministerio de Relaciones Exteriores de Colombia y la Universidad Nacional de Colombia, así como estudiantes de postgrado de la Pontificia Universidad Javeriana, de la Universidad Externado de Colombia, de la Universidad Autónoma de Colombia, y de la Universidad de la Sabana, todos aquí reunidos en una demostración del noble espíritu de cooperación inter-institucional, de la verdadera Universitas.

Extiendo al Claustro de la Universidad del Rosario, una de las más prestigiosas Universidades de Colombia y de América Latina, que está completando 353 años de existencia y densa trayectoria cultural e intelectual, mis más sinceros agradecimientos por la alta distinción que me concede, en esta bella Aula Máxima, repleta de historia y pensamiento, - distinción esta que para mí se reviste de gran significación no sólo profesional sino también personal. (...) Quisiera (...) pasar al tema de mi intervención en esta solenidad, que me permito denominar "Responsabilidad, Perdón y Justicia como Manifestaciones de la

\footnotetext{
${ }^{1}$ Trechos do discurso proferido pelo Autor na sessão solene da outorga do título de Professor Visitante Honoris Causa da Universidade Mayor de Nuestra Señora del Rosario, realizada em seu salão nobre, na cidade de Bogotá, Colômbia, na noite de 26 de janeiro de 2006.

2 Ph.D. (Cambridge); Juiz e Ex-Presidente da Corte Interamericana de Direitos Humanos; Professor Titular da Universidade de Brasília e do Instituto Rio-Branco; Doutor Honoris Causa pela Universidades Central do Chile, Católica do Peru, Americana do Paraguai, e Nacional de La Plata da Argentina; Membro Titular do Institut de Droit International e do Curatorium da Academia de Direito Internacional da Haia.
}

Revista Brasileira de Direito Internacional, Curitiba, v.3, n.3, jan./jun.2006 
Conciencia Jurídica Universal".

(...) En la reciente audiencia pública del 10 de marzo de 2005 en el caso Gutiérrez Soler (2005) ante la Corte Interamericana de Derechos Humanos, la Delegación de Colombia procedió a un emblemático gesto de pedido de perdón a las víctimas. Con todos los graves problemas que tiene ${ }^{3}$, Colombia se ha mantenido hasta la fecha fiel al sistema interamericano de protección que ayudó a construir, $y$, en las audiencias públicas ante la Corte, ha dado muestras de una postura constructiva hasta el presente. Tengo confianza en que seguirá siempre fiel a su valiosa tradición jurídica, dando fiel cumplimiento a las Sentencias de la Corte, para lo que cuenta con la solidariedad de los latinoamericanos, sobre todo ante la tragedia humana que vive.

\section{LA TRÍADA RESPONSABILIDAD/PERDÓN/JUSTICIA COMO MANIFESTACIÓN DE LA CONCIENCIA JURÍDICA UNIVERSAL}

A propósito de lo ocurrido en la referida audiencia pública del 10 de marzo de 2005, quisiera, ahora que diviso en el horizonte cercano el crepúsculo de la era de mi actuación como Juez titular de la Corte Interamericana, - la labor más gratificante de toda mi vida profesional, - trazar una breve línea de reflexiones sobre el despertar de la conciencia humana para los imperativos de protección de la persona humana y de reparación de los agravios contra esta perpetrados. Quisiera, en la noche de hoy en este acto académico en la Universidad del Rosario en Bogotá, referirme a la tríada responsabilidad/perdón/justicia como manifestación de la conciencia jurídica universal, - esta última como fuente material de todo el Derecho.

\footnotetext{
${ }^{3}$ Particularmente el de la violencia crónica, arraigado en su historia reciente; cf. G. Guzmán Campos, O. Fals Borda y E. Umaña Luna, La Violencia en Colombia - Estudio de un Proceso Social, 8a. ed., tomo I, Bogotá, Ed. Punta de Lanza, 1977, pp. 252, 294-297 y 416-418. Sobre los desplazamientos internos forzados, cf., v.g., ACNUR, Balance de la Política Pública de Prevención, Protección y Atención al Desplazamiento Interno Forzado en Colombia (2002-2004), Bogotá, ACNUR, 2004, pp. 15-361; y cf. M. Gómez Giraldo, Desterrados - las Cicatrices de la Guerra en Colombia, Bogotá, Intermedio, 2001, pp. 47-63 y 125-137. Sobre el proceso de desmovilización, cf., inter alia, J.A. Cárdenas Sarrias, Los Parias de la Guerra - Análisis del Proceso de Desmovilización Individual, Bogotá, Ed. Aurora, 2005, pp. 9-270; N. Springer, Desactivar la Guerra - Alternativas Audaces para Consolidar la Paz, Bogotá, Aguilar, 2005, pp. 21355.
}

Revista Brasileira de Direito Internacional, Curitiba, v.3, n.3, jan./jun.2006 


\subsection{RESPONSABILIDAD}

Todavía me acuerdo del primer caso de reconocimiento de responsabilidad internacional del Estado en audiencia pública ante la Corte Interamericana, en el caso Aloeboetoe y Otros versus Suriname (fondo, 1991), así como de las reuniones informales que lo precedieron, de las cuales participé, realizadas en el Hotel Aurola en San José de Costa Rica. Ya se pasaron 15 años, el caso ya fue archivado por la Corte después que Suriname, - país económicamente pequeño pero de respectable cultura, dió un bello ejemplo a los países grandes mediante el cabal cumplimiento de la Sentencia. Ya se pasaron 15 años desde aquel reconocimiento pionero y pleno, que fue, en aquel entonces, un evento ejemplarizante, con amplia repercusión en los círculos jusinternacionalistas latinoamericanos y caribeños.

Hoy día, de un total de 84 casos contenciosos tramitados ante la Corte Interamericana, se han resuelto $68, \mathrm{y}$, de este total, ya son 20 los casos de allanamiento bajo la Convención Americana, - de los cuales 15 casos de aceptación total de responsabilidad ${ }^{4}$ y 5 de aceptación parcial de responsabilidad ${ }^{5}$. Además, de los casos todavía en trámite ante la Corte, en 5 otros de ellos ha habido aceptación parcial de responsabilidad ${ }^{6}$. Esto significa que, en este inicio del año 2006, los Estados Partes a la Convención Americana y sometidos a la jurisdicción de la Corte Interamericana han logrado alcanzar una impresionante cifra de $29,76 \%$ de casos contenciosos ante la Corte en que ha habido reconocimiento de responsabilidad internacional, de los cuales $85 \%$ corresponden a aceptación total de responsabilidad y 11,90\% de aceptación parcial de responsabilidad.

Este porcentage no encuentra paralelo en la práctica de ningún otro

\footnotetext{
${ }^{4}$ Casos Aloeboetoe y Otros versus Suriname, Barrios Altos versus Perú, Benavides Cevallos versus Ecuador, Blanco Romero versus Venezuela, Bulacio versus Argentina, Caracazo versus Venezuela, Carpio Nicolle y Otros versus Guatemala, El Amparo versus Venezuela, Garrido y Baigorria versus Argentina, Gutiérrez Soler versus Colombia, Huilca Tecse versus Perú, Masacre de Plan de Sánchez versus Guatemala, Molina Theissen versus Guatemala, Myrna Mack Chang versus Guatemala, y Trujillo Oroza versus Bolivia.

${ }^{5}$ Casos Blake versus Guatemala, García Asto y Ramírez Rojas versus Perú, Gómez Palomino versus Perú, Maritza Urrutia versus Guatemala, y Masacre de Mapiripán versus Colombia.

${ }^{6}$ Casos Baldeón García versus Perú, Goiburú y Otros versus Paraguay, Ituango versus Colombia,Servellón García versus Honduras, y Vargas Areco versus Paraguay.
}

Revista Brasileira de Direito Internacional, Curitiba, v.3, n.3, jan./jun.2006 
tribunal internacional contemporáneo. No me consta que estos dados encontren paralelo o precedente en otros sistemas de protección internacional de los derechos humanos. Aquí, una vez más, los países latinoamericanos han dado muestras inequívocas y marcantes de su rica cultura jurídica, que no queda a deber nada a la europea y aún menos a la norteamericana. Todo lo contrario, constituyen hoy un ejemplo para otros países, en el presente dominio del Derecho Internacional, en beneficio de las personas protegidas. En varias de sus Sentencias en aquellos casos, la Corte Interamericana ha valorado positivamente dichas aceptaciones de responsabilidad internacional.

Me siento verdaderamente privilegiado en haber podido participar en la adjudicación de todos estos casos de reconocimiento de responsabilidad hasta la fecha, - desde el primero de ellos, la Sentencia del 04.12.1991 en el caso Aloeboetoe versus Suriname, - y acompañar así de muy cerca ese proceso alentador de concientización por parte de los Estados Partes en la Convención Americana de sus deberes de protección hacia todos los individuos que se encuentren bajo sus respectivas jurisdicciones. Este ha sido uno de los aspectos más gratificantes de mi labor de más de una década como magistrado de la Corte Interamericana, que identifico como manifestaciones de la propia conciencia humana, que, en última instancia, es la que hace avanzar el Derecho.

\subsection{PERDÓN}

Además, se multiplican significativamente los casos em que los Estados de nuestra región han pedido perdón a las víctimas, sea después de las respectivas Sentencias de la Corte, sea incluso antes de ellas, como, por ejemplo, lo hizo Colombia, de modo ejemplar, en el mencionado caso Gutiérrez Soler. Los países de nuestra región han, así, dado expresión al despertar de su conciencia, y han dado una muestra del renovado vigor de la respectable cultura jurídica latinoamericana y caribeña, - como bueno ejemplo a otros países, como los de América del Norte, que hasta el presente ni siquiera ratificaron la Convención Americana sobre Derechos Humanos.

Como apreciar tales pedidos de perdón en el marco del Derecho 
Internacional de los Derechos Humanos? Se enmarcan ellos, a mi modo de ver, ineluctablemente, a lo que me permito denominar la trilogía indisociable de responsabilidad/perdón/justicia, como manifestaciones de la conciencia jurídica universal, fuente material última del Derecho Internacional así como de todo el Derecho. En mi Voto Razonado en el caso Gutiérrez Soler versus Colombia (2005), me permití señalar (párrafos 19-28) la relevancia de la concientización, en nuestros días, de la importancia de la búsqueda del perdón por la perpetración de las graves violaciones de los derechos humanos. En una obra reciente, P. Ricoeur señala oportunamente que "c'est dans notre capacité à maîtriser le cours du temps que paraît pouvoir être puisé le courage de demander pardon"7; y evoca la reflexión de K. Jaspers, para quien "l'instance compétente, c'est la conscience individuelle"8. En efecto, si miramos con atención al mundo que nos circunda, en él encontraremos manifestaciones de la conciencia humana universal en reconocimiento inequívoco de la relevancia de la búsqueda del perdón, en distintos continentes.

En el continente americano, tal como fue señalado por la Corte Interamericana en la presente Sentencia sobre el caso Gutiérrez Soler, en la audiencia pública del 10 de marzo de 2005, los integrantes de la delegación del Estado demandado, reiteraron su reconocimiento de responsabilidad internacional en el cas d'espèce ${ }^{9}$, y pidieron perdón en nombre del Estado a la víctima y sus familiares en el cas d'espèce, a modo de contribuir, como fue expresado por la representación del Estado, a la "dignificación" de éstos últimos ${ }^{10}$.

Otro ejemplo significativo encuéntrase en la presentación de los resultados de la labor de la Comisión de la Verdad y Reconciliación de Chile. Al dar al público el Informe final de la Comisión, en marzo de 1991 (el cual planteó la necesidad de rehabilitación del honor de las víctimas), el entonces Presidente de Chile (Sr. Patricio Aylwin) observó, en su discurso, que era "la hora del perdón y la reconciliación", para mirar "hacia el futuro que nos une, más que al pasado que

\footnotetext{
${ }^{7}$ P. Ricoeur, La mémoire, l'histoire, l'oubli, Paris, Éd. du Seuil, 2000, p. 630.

${ }^{8}$ Cf. ibid., p. 616.

${ }^{9}$ Formulado anteriormente en su escrito del 09 de marzo de 2005.

${ }^{10}$ Párrafos 104 y 59, y cf. párr. 92(a) de la referida Sentencia.
}

Revista Brasileira de Direito Internacional, Curitiba, v.3, n.3, jan./jun.2006 
nos separe", y agregó:

"(...) Hay que empezar por precisar quiénes son los ofendidos llamados a perdonar y quiénes son los ofensores que han de ser perdonados. Yo no puedo perdonar por otros; el perdón no se impone por decreto. El perdón requiere arrepentimiento de una parte y de la otra generosidad. Cuando fueron agentes del Estado los que ocasionaron tanto sufrimiento, y los órganos competentes no pudieron o no supieron evitar o sancionarlos y tampoco hubo necesaria reacción social para impedirlo, son el Estado y la sociedad entera los responsables, bien sea por acción o por omisión. Es la sociedad chilena la que está en deuda con las víctimas de las violaciones de los derechos humanos. (...) Por eso yo me atrevo, en calidad de Presidente de la República, a asumir la representación de la nación entera para, en su nombre, pedir perdón a los familiares de las víctimas. Por eso también pido solemnemente a las fuerzas armadas y de orden y a todos los que hayan tenido participación en los excesos cometidos que hagan gestos de reconocimiento del dolor causado y colaboren para aminorarla"11.

En el continente asiático, recientemente, en la Cumbre de Países de África y Asia realizada en abril de 2005 en Jakarta, Indonesia, el Primer Ministro del Japón (Sr. J. Koizumi) pidió perdón a los victimados (sobre todo asiáticos) por los excesos perpetrados por los militares de su país en la II guerra mundial. En su discurso del 22.04.2005 en la referida Cumbre, expresó, en nombre del Estado japonés, sus sentimientos de "deep remorse" y "heartfelt apology always engraved in mind"12. Este no fue el primer gesto del género, por cuanto solicitudes similares de perdón fueron formuladas por los gobernantes de aquel país en ocasiones anteriores ${ }^{13}$.

A partir de diciembre de 1991, Japón emprendió una operación de factfinding, cuyos resultados fueron anunciados en julio de 1992 y agosto de 1993, sobre el tema denominado de "wartime comfort women"; al anunciarlos, las autoridades japonesas expresaron sus "sincere apologies and remorse" por la "grave afrenta al honor y a la dignidad" de las mujeres victimadas durante la guerra. Aceptando su "responsabilidad moral", Japón tomó una serie de

\footnotetext{
${ }^{11}$ P. Aylwin Azocar, "La Comisión de la Verdad y Reconciliación de Chile", in Estudios Básicos de Derechos Humanos - II (eds. A.A. Cançado Trindade y L. González Volio), San José de Costa Rica, IIDH, 1995, pp. 115-116, y cf. p. 113.

${ }_{12}$ Discurso reproducido in: www.infojapan.org/region/asia-paci/meet0504, el 22.04.2005, pp. 1-3.

${ }^{13}$ A saber, los días 29.09.1972, 24 y $26.08 .1982,06$ y 07.09.1984, 18.04.1990, 24 y 25.05.1990, 16 y 17.01.1992, 06.07.1992, 04 y 11.08.1993, 23.08.1993, 29.09.1993, 31.08.1994, 15.08.1995, 23.06.1996, 08.10.1996, 28.08.1997, 06.09.1997, 13 у 16.01.1998, 15.07.1998, 08.10.1998, 26.11.1998, 10 у 17.08.2000, 30.08.2000, 03.04.2001, 08.09.2001, 15.10.2001, 17.09.2002, 15.08.2003, 13.04.2005, y, en fin, 22.04.2005.
}

Revista Brasileira de Direito Internacional, Curitiba, v.3, n.3, jan./jun.2006 
iniciativas (a partir de julio de 1995), como el desarrollo de proyectos y fondos de asistencia a las víctimas (y familiares) en las Filipinas, República de Corea, Taiwan, Indonesia y Holanda, a fin de "ensure that such an issue may never be repeated"14.

En el continente europeo, en el año 2000, el Papa Juan Pablo II, en un documento histórico (titulado Memoria e Riconciliazione - La Chiesa e le Colpe del Passato), pidió perdón por las culpas de la Iglesia en el pasado. Explicó que

\footnotetext{
"Purificare la memoria significa eliminare dalla coscienza personale e collettiva tutte le forme di risentimento o di violenza che l'eredità del passato vi avesse lasciato $(\ldots)^{\prime 15}$.
}

Este proceso de purificación de la memoria se rige, en su formulación, por tres principios, a saber, el "principio de conciencia" (como un "juicio o imperativo moral") el "principio de historicidad", y el "principio de cambio de 'paradigma"'16. Entre los ejemplos históricos citados figuran los de las cruzadas (la "tragedia dell'uso delle armi per proteggere la fede"), de los indígenas, de la Inquisición, además de casos individuales como los de Giordano Bruno y Galileo $^{17}$.

En el continente africano, al recibir el Informe de la Comisión de la Verdad y Reconciliación de Sudáfrica, el Presidente de aquel país (Sr. Nelson Mandela), en discurso pronunciado en Pretoria el 29.10.1998, advirtió:

\begin{abstract}
"It will be difficult for the victims of gross violations of human rights to accept the philosophical account of the trade-off between punitive justice and a peaceful transition. It may be difficult for many to accept the finding the apartheid State was the primary perpetrator of gross human rights violations. Yet if we are true to our founding pact, we cannot equivocate about a system which exacted such inhumanity. There can be no dissonance with regard to the clarion call: never again!"18.
\end{abstract}

\footnotetext{
${ }^{14}$ Datos constantes de un dossier (de marzo de 2003, pp. 1-6) que recebí del Ministerio de Relaciones Exteriores del Japón, en Tokyo, durante mi visita académica a aquel país, como invitado oficial, en diciembre de 2004.

${ }^{15}$ Commissione Teologica Internazionale/Vaticano,] Memoria e Riconciliazione - La Chiesa e le Colpe del Passato: Il Papa Chiede Perdono - Purificare la Memoria, Roma, Ed. Piemme, 2000, p. 98.

${ }_{17}^{16}$ Ibid., pp. 98-99.

${ }^{17}$ Cf. ibid., pp. 131-180. Y cf. también John Paul II, Crossing the Threshold of Hope, N.Y., Knopf, 2004, pp. 63-66; Dalai Lama y V. Chan, The Wisdom of Forgiveness, N.Y. Riverhead Books, 2004, pp. 234-236.

${ }^{18}$ South African Government, www.info.gov.za/index, Statement of 29 October 1998, p. 2.
}

Revista Brasileira de Direito Internacional, Curitiba, v.3, n.3, jan./jun.2006 
Poco después, en su evaluación de la labor de la Comisión de la Verdad y Reconciliación sudafricana, publicada en enero de 1999, el Arzobispo Desmond Tutu concentró sus reflexiones en el tema del arrepentimiento y la búsqueda del perdón. Ponderó él que

\begin{abstract}
"Forgiveness and reconciliation are not the normal terms of political discourse. They are playing on home ground in the religious area (...) to bear on the delicate business of healing a traumatised and deeply wounded people. (...) Forgiveness in an important way is making it possible for the wrongdoer to make a new beginning and not to be imprisoned in a paralysing past. (...) But the only way forgiveness can be appropriated is by the perpetrator confessing because he is penitent. Something similar is true for communities and people"19.
\end{abstract}

En seguida, el Arzobispo D. Tutu se refirió a la tragedia de Ruanda:

\begin{abstract}
"I visited Rwanda soon after the genocide there. I said that if retributive justice was to be the last word in dealing with that awful happening, then Rwanda had had it, for her history has been one of reprisal followed by counter-reprisal, as first Tutsi and then Hutu took the opportunity for revenge, as each in turn toppled the previous top dogs. Their hope lay in something which went beyond retributive justice, and that something was forgiveness. (...) And so we see that without forgiveness there can be no future" 20 .
\end{abstract}

En su decisión emitida en Arusha, el 02.10.1998, en el caso Prosecutor versus Akayesu ${ }^{21}$ el Tribunal Penal Internacional ad hoc para Ruanda (Trial Chamber) señaló que el acusado (Sr. J.-P. Akayesu), condenado a prisión por el Tribunal (párrafo 3), a pesar de haber aceptado responsabilidad por los hechos tan sólo por omisión (por falta del cumplimiento del deber de proteger la población de Taba), sin embargo insistió en "publicamente expresar pesar por todas las víctimas de los trágicos eventos que ocurrieron en Ruanda, sea tutsis, hutus, o twas. Pidió el perdón del pueblo de Ruanda en general y específicamente del pueblo de la comuna de Taba (...)" (párrafo 2).

\footnotetext{
${ }^{19}$ D. Tutu, "Seeking Reconciliation in South Africa", in Franciscan magazine, European Province of the Society of Saint Francis (January 1999 issue), reproducido in: www.franciscans.org.uk/1999jantutu, pp. 1 y 3.

${ }^{20}$ Ibid., p. 3.

${ }^{21}$. Caso n. ICTR/96-4-T.
}

Revista Brasileira de Direito Internacional, Curitiba, v.3, n.3, jan./jun.2006 


\section{$2.3 \mathrm{JUSTICIA}$}

El perdón, de suma importancia como otra de las manifestaciones de la conciencia humana, sin embargo no puede ser apreciado de modo aislado: encuéntrase ineluctablemente vinculado a la responsabilidad - a la cual ya me referí, - así como a la justicia, tercer dato de la tríada que me propongo aquí desarrollar. Así como en pasar del tiempo es, de cierto modo, una medicina doloris, el perdón es un acto de redención y de liberación (de la punición de la vida interior), de parte tanto de las víctimas como de sus victimarios arrependidos, es un intento de superación de la miseria de la condición humana ${ }^{22}$.

El perdón es pedido por los victimarios arrependidos, pero puede ser aceptado o no por las víctimas. Estas esperan tener sus sufrimientos reivindicados, de conformidad con las lesiones sufridas; para algunas, el pedido de perdón puede ser considerado como un acto satisfactorio de justicia. Pero, para otras, víctimas de violaciones particularmente graves, el perdón debe ser acompañado de otros actos de justicia que reivindiquen y reconozcan debidamente sus sufrimientos, y pongan fin a la impunidad.

En un libro magistral, - de aquéllos que ya no se escriben más en nuestra nueva era de la informática, - titulado Le problème du mal - l'histoire (1948), en que su lúcido autor, R.P. Sertillanges, observó con acierto que el pensamiento positivista, insensible a los valores, se tornó simplemente inconsciente del problema del maf3. El despertar de la conciencia jurídica universal viene, a mi modo de ver, a sepultar en definitiva la indiferencia de la miopía del positivismo jurídico, - siempre connivente con el poder, y sumiso al mismo, inclusive cuando es ejercido en grave violación de los derechos básicos inherentes a la persona humana.

Todo el capítulo de las reparaciones de violaciones de los derechos humanos requiere un mayor desarrollo conceptual y jurisprudencial, a partir del reconocimiento de la estrecha relación entre los derechos a la verdad, a la reparación y a la justicia. Tal desarrollo se impone particularmente ante

\footnotetext{
${ }^{22}$ V. Jankélévitch, Forgiveness, Chicago, University of Chicago Press, 2005, pp. 10, 39, 41 y 144.

${ }^{23}$ R.P. Sertillanges, Le problème du mal - l'histoire, Paris, Aubier, 1948, p. 292, y, para la importancia de los valores, cf. pp. 395-397.
}

Revista Brasileira de Direito Internacional, Curitiba, v.3, n.3, jan./jun.2006 
violaciones graves y sistemáticas de los derechos humanos, que requieren reparaciones de cuño disuasivo, precisamente para garantizar la no-repetición de las graves violaciones de los derechos humanos.

La jurisprudencia de la Corte Interamericana en materia de reparaciones es particularmente rica, $y$, en los últimos años, ésto ha sido objeto de reconocimiento internacional por parte de la doctrina especializada. Sin embargo, aún resta un largo camino que recorrer. Por ejemplo, todo este capítulo fue erigido, en otras areas del Derecho, a partir de la óptica de reparación de daños, con base en una analogía inadecuada con soluciones propias del Derecho Civil, y no de reparación del sufrimiento humano.

La determinación de los hechos se reviste de fundamental importancia para los victimados y sus familiares. En los últimos años, la Corte Interamericana ha advertido para la importancia del derecho a la verdad, en sus dimensiones tanto individual ${ }^{24}$ (como medio de reparación para la víctima y sus familiares) como social (que atañe a todo el tejido social). A partir de la Sentencia sobre reparaciones en el memorable caso Bámaca Velásquez versus Guatemala (del 22.02.2002), - célebre caso de tanta densidad cultural, - la Corte pasó a señalar también la dimensión social (a la par de la individual) del derecho a la verdad, al ponderar que

"La sociedad tiene el derecho a conocer la verdad en cuanto a tales crímenes con el propósito de que tenga la capacidad de prevenirlos en el futuro" (párr. 77).

Desde entonces la Corte ha reiterado dicha dimensión social en sucesivas Sentencias ${ }^{25}$. El derecho a la verdad se vincula al deber ineludible del

\footnotetext{
${ }^{24}$ La dimensión individual ha sido señalada por la Corte desde sus Sentencias en los casos Castillo Páez versus Perú (del 03.11.1997, párr. 90), Bámaca Velásquez versus Guatemala (del 25.11.2000, fondo, párr. 201), Barrios Altos referente al Perú (del 14.03.2001, párrs. 47-48), Paniagua Morales y Otros versus Guatemala (del 25.05.2001, reparaciones, párr. 200), Villagrán Morales y Otros ("Niños de la Calle") versus Guatemala (del 26.05.2001, reparaciones, párr. 100), Cantoral Benavides versus Perú (del 03.12.2001, reparaciones, párr. 69), Bulacio versus Argentina (del 18.09.2003, párr. 114), Molina Theissen versus Guatemala (del 03.07.2004, reparaciones, párrs. 80-81), y Hermanos Gómez Paquiyauri versus Perú (del 08.07.2004, párrs. 229-230).

${ }^{25}$ En los casos Trujillo Oroza versus Bolivia (del 27.02.2002, reparaciones, párr. 114), Myrna Mack Chang versus Guatemala (del 25.11.2003, párr. 274), 19 Comerciantes versus Colombia (del 05.07.2004, párr. 259), Masacre de Plan de Sánchez relativo a Guatemala (del 19.11.2004, reparaciones, párr. 98), Carpio Nicolle y Otros versus Guatemala (del 22.11.2004, párr. 128),
}

Revista Brasileira de Direito Internacional, Curitiba, v.3, n.3, jan./jun.2006 
Estado de realizar una investigación seria y efectiva de los hechos que generaron las violaciones de los derechos humanos e identificar, juzgar y sancionar a los responsables, para evitar la indefensión de las víctimas y de sus familiares, y garantizar la no-repetición crónica de las violaciones de sus derechos.

En cuanto a las reparaciones, quisiera aqui rescatar algunas de las reflexiones que me permití desarrollar en mi Voto Razonado en el caso de los "Niños de la Calle" (Villagrán Morales y Otros versus Guatemala, reparaciones, 2001). Al destacar la relevancia de la satisfacción, como forma de reparación nopecuniaria a los familiares inmediatos de las víctimas asesinadas (párr. 27), agregué:

\begin{abstract}
"Cuál es el precio de una vida humana? Cuál es el precio de la integridad de la persona humana? Cuál es el precio de la libertad de conciencia, o de la protección de la honra y de la dignidad? Cuál es el precio del dolor o sufrimiento humano? Si se pagan las indemnizaciones, el"problema" estaría "resuelto"? Lo cierto es que todos los derechos protegidos bajo la Convención Americana sobre Derechos Humanos tienen un valor autónomo y un contenido jurídico propio, y además, encuéntranse todos relacionados inter se, indivisibles que son. (...) El día en que la labor de determinar las reparaciones debidas a las víctimas de violaciones de derechos humanos fundamentales se reduciese exclusivamente a una simple fijación de compensaciones en la forma de indemnizaciones, (...) la propia labor de un tribunal internacional de derechos humanos estaría irremediablemente desprovista de todo sentido. (...)

(...) La vida y la integridad de cada ser humano efectivamente no tienen precio. Tampoco tienen precio la libertad de conciencia, la protección de la honra y de la dignidad de la persona humana. Y tampoco tiene el precio el dolor o sufrimiento humano. El mal perpetrado en lãs personas de las víctimas (directas e indirectas) no es removido por las reparaciones: las víctimas siguen siendo víctimas, antes y después de las reparaciones, - por lo que se impone mayor importancia a ser atribuída a las medidas en pro de su rehabilitación.

En cuanto, particularmente, a los familiares inmediatos de víctimas directas de violaciones de derechos humanos, temo que sólo a través del intenso sufrimiento asumido (que me parece tener un efecto sobre todo autodidáctico) podrán, como víctimas indirectas, frente a la pérdida de un ser querido, agravada por la extrema violencia, reconstruir su vida interior, - la cual es el único lugar seguro donde cada uno puede refugiarse de las injusticias y los insultos de ese mundo. Pero el mal cometido no desaparece por el otorgamiento de reparaciones, y sigue afectando a los familiares inmediatos de la persona torturada y asesinada en sus relaciones entre sí, y con otras personas, y con el mundo exterior. Las víctimas directas han sufrido un daño irreparable, al haber sido privadas de su vida arbitrariamente (en los términos del artículo 4(1) de la Convención Americana sobre Derechos Humanos).

Pero también las víctimas indirectas (padres, hijos, cónyuges, y, en determinadas
\end{abstract}

Hermanas Serrano Cruz versus El Salvador (del 01.03.2005, párrs. 62 y 169), Huilca Tecse versus Perú (del 03.03.2005, párr. 107), Comunidad Moiwana versus Suriname (del 15.06.2005, párr. 204), Gutiérrez Soler versus Colombia (del 12.09.2005, párr. 96), Masacre de Mapiripán referente a Colombia (del 15.09.2005, párr. 298), y Blanco Romero y Otros versus Venezuela (del 28.11.2005, párr. 93). 
circunstancias, hermanos) han sufrido una pérdida irreparable, pues sus vidas nunca más serán las mismas. (...) La realización de la justicia contribuye al menos a estructurar su psiquismo, redespertar su fe y esperanza, y ordenar las relaciones humanas con sus próximos. Todo verdadero jurista tiene, así, el deber ineluctable de dar su contribución a la realización de la justicia, desde la perspectiva de la integralidad de la personalidad de las víctimas.

Mi conclusión es en el sentido de que, en circunstancias como las del presente caso de los Niños de la Calle, no hay, stricto sensu, reparación verdadera o plena posible, en el sentido literal del término (del latín reparatio, derivado de reparare, "preparar o disponer de nuevo"), lo que revela los límites del Derecho (a ejemplo de los límites de otras ramas del conocimiento humano). (...)

La imposibilidad de una plena reparación - la restitutio in integrum - se verifica, en mi entendimiento, no sólo en cuanto a las víctimas directas y al derecho fundamental a la vida, como comúnmente se supone, sino también en cuanto a las víctimas indirectas (sobrevivientes) y a otros derechos (como el de no ser sometido a tortura, ni a tratos crueles, inhumanos o degradantes).

Jurídicamente, sobre todo en circunstancias como las del presente caso de los Niños de la Calle, las reparaciones - de las consecuencias de la medida o situación lesiva de los derechos humanos protegidos (en los términos del artículo 63(1) de la Convención Americana), - en lugar de verdaderamente reparar, más bien alivían el sufrimiento humano de los familiares sobrevivientes, buscando rehabilitarlos para la vida, - y por eso tórnanse absolutamente necesarias.

Es éste, en mi entender, el verdadero sentido, con las inevitables limitaciones de su real alcance, de que se reviste el concepto jurídico de reparaciones, en el marco del Derecho Internacional de los Derechos Humanos. El mal cometido, como ya señalé, no desaparece: es tan sólo combatido, y mitigado. Las reparaciones otorgadas tornan la vida de los familiares sobrevivientes quizás soportable, por el hecho de que, en el caso concreto, el silencio y la indiferencia y el olvido no han logrado sobreponerse a las atrocidades, y de que el mal perpetrado no ha prevalecido sobre la perenne búsqueda de la justicia (propia del espíritu). En otras palabras, las reparaciones otorgadas significan que, en el caso concreto, la conciencia humana ha prevalecido sobre el impulso de destrucción. En este sentido, las reparaciones, aunque no plenas, se revisten de innegable importancia en la labor de la salvaguardia de los derechos inherentes al ser humano" (párrs. 36-43).

\section{LA EMANCIPACIÓN DEL INDIVIDUO VIS-À-VIS SU PROPIO} ESTADO:

EL ACCESO DIRECTO DE LA PERSONA HUMANA A LA JUSTICIA INTERNACIONAL.

Todo el desarrollo jurisprudencial y conceptual en ese sentido - y es ésta mi última reflexión - ha sido impulsado por la propia persona victimada, emancipándose de ese modo de su propio Estado, como verdadero sujeto del derecho tanto interno como internacional. Esa gran conquista del espíritu humano se ha reflejado en el actual Reglamento de la Corte (del 24.11.2000, en vigor 
desde el 01.06.2001), con el otorgamiento del locus standi in judicio a los peticionarios, en todas las etapas del procedimiento ante la Corte, quizás el avance jurídico-procesal más importante en pro del perfeccionamiento del mecanismo de protección de la Convención Americana desde su entrada en vigor hace más de un cuarto de siglo.

Dicho avance se consolidará el día en que sea plasmado en definitivo en un Protocolo de enmiendas a la Convención Americana sobre Derechos Humanos reconociendo el jus standi de los individuos, su acceso directo a la Corte, - como vengo sosteniendo por tanto tiempo ${ }^{26}$. Aquí, una vez más, los avances ya logrados hasta la fecha son manifestaciones de la conciencia humana, para atender a una real necesidad de protección de los seres humanos.

Estos avances, a mi juicio, forman parte de un proceso más amplio, de humanización del Derecho Internacional, de reconstrucción de un nuevo jus gentium, en la línea de un jusnaturalismo renovado, en este inicio del siglo XXI, como sostuve el año pasado en la Academia de Derecho Internacional de la Haya, en mi Curso General de Derecho Internacional Público (del 25 de julio al 12 de agosto de 2005), que tuvo por subtítulo "El Derecho Internacional para la Humanidad - Rumo a un Nuevo Jus Gentium"27. Es esta una tarea que me parece crucial en nuestros días, en un mundo dilacerado por conflictos y disparidades, de modo a tornar el Derecho Internacional capaz de responder a las necesidades y aspiraciones de la humanidad en la actualidad. (...)

Bogotá, 26 de enero de 2006.

A.A.C.T.

\footnotetext{
${ }^{26}$ A.A. Cançado Trindade, Bases para un Proyecto de Protocolo a la Convención Americana sobre Derechos Humanos, para Fortalecer Su Mecanismo de Protección, vol. II, 2a. ed., San José de Costa Rica, Corte Interamericana de Derechos Humanos, 2003, pp. 1-1015, esp. pp. 3-64.

${ }_{27}$ A.A. Cançado Trindade, "General Course on Public International Law - International Law for Humankind: Towards a New Jus Gentium", in Recueil des Cours de l'Académie de Droit International (2005), capítulos I-XXVII, 997 pp. (en prensa).
}

Revista Brasileira de Direito Internacional, Curitiba, v.3, n.3, jan./jun.2006 